\title{
Phylogenic Study of Genus Phyllostachys (Phyllostachys) in Korea by Internal Transcribed Spacer Sequence (ITS)
}

\author{
Song Jin Lee', Man Kyu Huh² ${ }^{2}$, Hong Wook Huh ${ }^{1}$ and Byeong Ryong Lee ${ }^{3}$ \\ ${ }^{1}$ Department of Science Education, Busan National University, Busan 609-735, Korea \\ ${ }^{2}$ Department of Molecular Biology, Dongeui University, Busan 614714, Korea \\ ${ }^{3}$ Department of Science Education (Bidogy), Seowon University, Chengiu 361-742, Korea
}

Received July 11, 2011 /Revised September 1, 2011 /Accepted September 2, 2011

\begin{abstract}
Phyllostachys consists of high and fast growing trees and is a genus in the family Gramineae. The genus has many species in Asia, with main distribution being in India and China. One of the most popular sequences for phylogenetic inference at the generic and infrageneric levels in plants is the internal transcribed spacer (ITS) region of the 18S-5.8S-26S nuclear ribosomal cistron. We evaluated four taxa with the ITS region to estimate phenotypic relationships within the genus Phyllostachys in Korea. Alignment of the DNA sequences required the addition of numerous gaps. Sequence variation within the Phyllostachys was mostly due to natural selection, although several indels and inserts were found. Within the genus Phyllostachys, P. nigra and P. nigra var. henonis were the relatives in the three phylogenetic analyses (MP, ML, and NJ). However, some external nodes were poorly supported. Morphological traits and simple repeats (ISSR) represented the result of a relationship similar to the that of ITS sequences in the genus Phyllostachys. This suggests that ITS sequences are very informative for identification of these taxa.
\end{abstract}

Key words : Genus Phyllostachys, internal transcribed spacer (ITS), phylogenetic analyses

\section{서 론}

벼과 또는 화본과(Genus Gramineae or Poaceae)에 속하는 왕대속(genus Phyllostachys Siebold et Zuccarini)에는 왕대 또 는 참대(Phyllostachys bambusoides Siebold et Zuccarini), 오죽 (Phyllostachys nigra Munro), 분죽 또는 솜대(Phyllostachys nigra (Lodd.) Munro var. henonis (Bean) Stapf), 죽순대 또는 맹종죽(Phyllostachys pubescens Mazel)이 있다[9]. 이 속과 근연 한 해장죽속(Genus Arundinaria Michaux)에는 문수조릿대 (Arundinaria munsuensis Y. Lee), 해장죽(Arundinaria simonii (Carr.) Riviere)이 있다. 이들 속의 식물보다는 키가 작은 조릿 대속(Genus Sasa Makino et Shibata)에는 조릿대(Sasa borealis (Hack.) Makino), 고려조릿대(Sasa coreana Nakai), 이대(Sasa japonica (Sieb. \& Zucc.) Makino), 자주이대(Sasa japonica (Sieb. \& Zucc.) var. purpurascens Nakai), 섬조릿대(Sasa kurilensis (Rupr.) Makino et Shibata), 제주조릿대(Sasa quelpaertensis Nakai)가 있다. 해장죽속이나 조릿대속은 일부 재배되고 있지 만 왕대속은 인도와 중국에 30여 종이 자생 또는 재배하고 있으나 우리나라에는 4종으로 달리 모두 재배되고 있다[9].

Nuclear ribosomal DNA internal transcribed spacer sequences (ITS)는 Baldwin et al. [2]에 의해 ITS1-5.8S-ITS2 부위

\section{*Corresponding author}

Tel : +82-51-890-1529, Fax: +82-51-890-1521

E-mail : mkhuh@deu.ac.kr
가 완전 서열화 되어 진화관계를 수반한 상위 분류군에 많이 이용되고 있다[1,3,4,11]. 특히 PCR의 발전과 더불어 한 번에 $1 \mathrm{~kb}$ 정도의 서열을 벡터에 주입하여 클로닝을 거칠 필요가 없게 되었다. 따라서 $1 \mathrm{~kb}$ 크기 이하인 ITS는 ITS1/ITS2, ITS3/4의 시발체(primer)가 정형화되어 있을 정도[18]로 이 핵 내 리보솜 서열이 많이 이용되고 있어 유전자은행에서 비교 검색이 가장 활발한 부위 중 하나이다[11].

국내에서도 분자 마커를 이용한 여러 식물종에 대한 계통분 류학적 연구가 진행되고 있으며 특히 왕대 속 식물 4 개 분류군 에 대해 계통분석 연구를 수행한 바 있다[7,8]. 그러나 이 두 마크 간에 같은 분류군의 위치와 일부 분지군이 tree상에 일치 하지 않은 점이 있었다. 이에 ITS1-5.8S-ITS2 부위서열을 이용 한 왕대 속 식물 4 개 분류군에 대한 유연관계를 실행하였으며 그 결과에 따라 형태학적으로 학명 부여에 대한 본 연구에서 토의를 하였다.

\section{재료 및 방법}

\section{재료와 genomic DNA 추출}

본 분석에 사용한 식물 분류군은 왕대 또는 참대 (Phyllostachys bambusoides Siebold et Zuccarini), 오죽 (Phyllostachys nigra Munro), 분죽 또는 솜대(Phyllostachys nigra (Lodd.) Munro var. henonis (Bean) Stapf), 죽순대 또는 맹종죽(Phyllostachys pubescens Mazel)이다. $1,000 \mathrm{~m}^{2}$ 이상 되 
Table 1. Taxa used in the molecular study of the genus Phyllostachys including population locations

\begin{tabular}{cll}
\hline Code & Scientific name & Geographic origin \\
\hline 1 & Phyllostachys bambusoides Siebold et Zuccarini & Hwangjeon-ri, Masan-myeon, Gurye-gun, Jeollanam-do \\
2 & Phyllostachys nigra Munro & Jukheon-dong, Gangneung-si, Gangwon-do \\
3 & $\begin{array}{l}\text { Phyllostachys nigra (Lodd.) Munro var. henonis } \\
\text { (Bean) Stapf }\end{array}$ & Cheonbyeon-ri, Damyang-eup, Damyang-gun, Jeollanam-do \\
4 & Phyllostachys pubescens Mazel & Hyanggyo-ri, Damyang-eup, Damyang-gun, Jeollanam-do \\
\hline
\end{tabular}

는 유효집단을 유지하고 있는 재배지에서 직접 채집하여 사용 하였다(Table 1).

각 식물체로부터 DNA를 추출하기 위하여 Plant DNA Zol Reagent (Life Technologies Inc., Grand Island, New York, $\mathrm{USA}$ )를 사용하였다 추출방법은 $0.3 \mathrm{~g}$ 의 신선한 잎을 액체질소 로 마쇄한 다음 사용자의 지침서에 의거하여 DNA를 추출하 였다. 추출된 DNA는 에탄올 등 여액의 제거를 위해 진공 흡입 기로 5 분간 건조시킨 후 $\mathrm{TE} 100 \mathrm{ul}$ 에 용해하여 3 일간 냉장 보관하였다. 용해된 시료는 DyNA 200 fluorometer (Amersham Pharmacia Biotech, USA)를 이용하여 DNA 정량 을 체크하였고 $\mathrm{TE}$ 로 $\mathrm{DNA}$ 농도가 균질하게 조정하여 본 분석 을 위해 사용하거나 $-20^{\circ} \mathrm{C}$ 냉동고에 보관하였다.

\section{ITS 분석}

엽록체의 ITS 부위는 White 등[18]이 고안한 시발체 (primer)로 PCR (polymerase chain reaction)을 이용하여 증폭 시켰다(Table 2).

$\mathrm{PCR}$ 반응을 위하여 추출한 각 분류군의 게놈 DNA $50 \mathrm{ng}$, 각 $\mathrm{dNTP} 100 \mathrm{uM}$, 시발체 각 $0.2 \mathrm{uM}, 1 x$ enzyme buffer, Taq polymerase 2 unit를 넣고 증류수로 전체 $50 \mathrm{ul}$ volume이 되도 록 추가하였다. 증폭반응은 초기 $94^{\circ} \mathrm{C}$ 에서 $90 \mathrm{sec}$ 간 변성한 후, 28 사이클로 $94^{\circ} \mathrm{C}$ 에서 $30 \mathrm{sec}, 42^{\circ} \mathrm{C}$ 에서 $60 \mathrm{sec}, 72^{\circ} \mathrm{C}$ 에서 $60 \mathrm{sec}$ 간 실시하였고, 추가로 $72{ }^{\circ} \mathrm{C}$ 에서 5 분간 연장하였다.

$\mathrm{PCR}$ 산물은 $1.5 \%$ agarose gel에서 분리하였는데 이때 절 편들의 상대적 크기를 비교하기 위해 $100 \mathrm{bp}$ ladder DNA marker를 같이 loading시켰다. 전기영동 후 젤은 ethidium bromide로 염색하여 밴드를 현상하였다. 현상된 젤은 Alpha Image TM (Alpha Innotech Co, San Leandro, CA, $\mathrm{USA})$ 을 사용하여 밴드 양상을 조사하였다. 이후 젤에서

Table 2. Synthetic primer sequencing $\left(5^{\prime}-3^{\prime}\right)$ used for the ITS analysis in this study

\begin{tabular}{clc}
\hline Name & \multicolumn{1}{c}{ Sequence 5'-3' $^{\prime}$} & \multicolumn{2}{c}{ Code } \\
\hline ITS1 & $5^{\prime}$-TCCGTAGGTGAACCTGCGG-3' & White (1990) \\
ITS2 & $5^{\prime}$-GCTGCGTTCTTCATCGATGC-3' & White (1990) \\
ITS3 & $5^{\prime}$-GCATCGATGAAGAACGCAGC-3' & White (1990) \\
ITS4 & $5^{\prime}$-TCCTCCGCTTATTGATATGC-3' & White (1990) \\
\hline
\end{tabular}

DNA를 QIAquick Gel Extraction Kit (QIAGEN)로 추출하 였다. 증폭된 단편들은 bluescript vector로 클론하였고, $\mathrm{ABI}$ Prism 377 Sequencer (Applied Biosystem, Foster City, CA, $\mathrm{USA}$ 로 서열화하였다. 각각의 종에서 최소 10 개체 클론들 을 분석하였다.

\section{통계 분석}

분류군간 유전적 거리 $(I)$ 와 유전적 동질성 $(D)$ 은 분류군간 염기쌍의 비교로 산출하였다[12]. PAUP에서 분류군간 핵산 차이에 의한 유의성 검증, 염기 빈도, 서열쌍 거리, uncorrected "p"에 의한 측정된 거리 등을 산출하였다[15]. 염기 자리 당 서열 간 염기 조성 차이, 불일치 계수를 검증하였다[6].

핵산치환 모델 분석은 최적 치환 패턴에 대한 최소 Bayesian Information Criterion (BIC) 값을 고려하였다. 각 모 델에 대해 Akaike Information Criterion, corrected (AICc) 값, Maximum Likelihood value $(\ln L)$, 척도의 수는 Nei와 Kumar [13]의 식에 의거하였다. 염기 자리 간 진화율에 대한 비균등성 은 진화적으로 비변이 부분 $(+I)$ 을 가진 Gamma 분포 $(+G)$ 로 나타낸 모델을 사용하였다. 염기치환의 전이/전형의 비율에 대한 평가 $(R)$ 역시 이 모델에 근거하여 산출하였다.

서열간 코돈의 중립성 검증은 갭과 결손 서열을 제외하고 1,000 회 반복으로 MEGA5로 실시하였다[17]. 타지마의 여러 통계치(M=number of sites, $\mathrm{S}=$ Number of segregating sites, $\mathrm{ps}=\mathrm{S} / \mathrm{M}$, and $\pi=$ nucleotide diversity, $\mathrm{D}=$ Tajima test statistic) 를 산출하였다[16].

\section{유연관계 분석}

각 왕대속 식물종 ITS에서 얻은 크로마토그램(chromatogram)은 소프트웨어 Sequence Navigator 1.0.1 (Applied Biosystems Inc.)로 편집하였다. 왕대속 ITS 서열에서 결손부 위를 포함한 서열 배당은 MEGA5와 Clustal X program으로 분석하였다[23]. 배당된 서열에서 gap의 부위는 missing data 로 처리하였다. 그러나 계통학적으로 정보적인 인델은 이진법 처리로 데이터에 삽입하였다.

최절약법에 의한 tree (maximum parsimonious tree, $\mathrm{MP}$ ) 는 heuristic search, branch-swapping options, tree bisection-reconnection에 따랐다[15]. 최우법(maximum like- 
lihood tree, ML), N-J법(neighbor-joining tree, NJ)으로 tree 작성을 실시하여 비교하였다. 계통분석의 분지는 PHYLIP version 3.57의 NEIGHBOR, neighbor-joining (NJ) 방법에 의 해 구성하였다[5,14]. 분류군의 가지에 대한 Bootstrap 분석은 500 회 반복법으로 실시하였다.

\section{결 과}

왕대속 4 개 분류군에 대한 ITS 부위의 profiles는 $100 \mathrm{bp}$ ladder DNA marker로 크기를 비교한 결과 평균 671 nucleotides (bp)의 크기를 가지고 있었다. 이들 밴드를 purification 하여 DNA 염기서열을 분석한 결과 왕대속 식물은 653-751 $\mathrm{bp}$ 이었다. 최고와 최저의 차이는 삽입과 결실에 의한 것이다.

$\mathrm{A}+\mathrm{T}$ 함량은 $42.2-51.5 \%$ 였으며(Table 3 ), 분류군간 염기 차 이는 4 분류군 염기 A, C, G, T 어디에서도 유의성을 나타내지 않았다.

서열 쌍 거리 분석에서 오죽과 분죽이 유전적 거리가 0.269 로 가장 근연하였다(Table 4). 반면에 맹족중과 오죽이 유전적 거리가 1.251 로 가장 먼 유연관계를 나타내었다. 맹족죽은 나 머지 분류군의 쌍에 비해 유전적 거리가 높았다.

모든 염기 자리 당 불일치 지수(disparity index) 또는 불균 등 지수를 산출하였다(Table 5). 0 보다 클 경우 서열 간 진화 분화의 차이가 우연에 의한 예상 값보다 염기 조성 편향에서

Table 4. The sequence pair distances of sites between two sequences in a multiple alignment among species of genus Phyllostachys using ITS analysis

\begin{tabular}{ccccc}
\hline Taxa & 1 & 2 & 3 & 4 \\
\hline 1 & - & & & \\
2 & 1.251 & - & & \\
3 & 1.196 & 0.269 & - & \\
4 & 1.222 & 0.461 & 0.356 & - \\
\hline
\end{tabular}

The taxon codes of first line are the same as those of first column.

The taxon codes from 1 to 4 are the same as Table 1 .
Table 5. The disparity index (below diagonal) per site and index test (upper diagonal) for all sequence pairs in genus Phyllostachys using ITS analysis

\begin{tabular}{ccccc}
\hline Taxa & 1 & 2 & 3 & 4 \\
\hline 1 & - & 1.000 & 0.066 & 0.170 \\
2 & 0.000 & - & 0.026 & 1.000 \\
3 & 0.518 & 0.581 & - & 0.000 \\
4 & 0.268 & 0.000 & 1.924 & - \\
\hline
\end{tabular}

The taxon codes of first line are the same as those of first column.

The taxon codes from 1 to 4 are the same as Table 1 .

Table 6. Maximum likelihood estimate of the pattern of nucleotide sequences

\begin{tabular}{ccccc}
\hline Base & $\mathrm{A}$ & $\mathrm{T}$ & $\mathrm{C}$ & $\mathrm{G}$ \\
\hline $\mathrm{A}$ & - & 6.22 & 7.78 & 10.47 \\
$\mathrm{~T}$ & 6.24 & - & 14.31 & 6.94 \\
$\mathrm{C}$ & 6.24 & 11.44 & - & 6.94 \\
$\mathrm{G}$ & 9.41 & 6.23 & 7.78 & - \\
\hline
\end{tabular}

Each entry shows the probability of substitution (r) from one base (row) to another base (column). For simplicity, the sum of $r$ values is made equal to 100. Rates of different transitional substitutions are shown in bold and those of transversionsal substitutions are shown in italics. Codon positions included were $1 s t+2 n d+3 r d+$ Noncoding. All positions containing gaps and missing data were eliminated. There were a total of 751 positions in the final dataset. Evolutionary analyses were conducted in MEGA5. The taxon codes from 1 to 4 are the same as Table 1.

큰 차이를 나타내게 된다. 0.05 보다 작을 경우 서열이 같은 패턴을 가지고 진화했다는 귀무가설을 수용할 수 없는데 맹종 죽과 오죽, 오죽과 왕대의 비교에서 그런 결과가 나타났다.

$\mathrm{DNA}$ 서열에서 염기 치환이 같은 패턴으로 진화해왔다는 가설을 몬테-카를로 테스트(1,000 반복)로 검증하였다(Table 6). T에서 $\mathrm{C}$ 로 치환이 14.31 로 가장 높았으며 반대인 경우도 11.44 로 높았다. 또한 치환에 대한 24 핵산 치환 모델을 적용하

Table 3. The chi-square test of homogeneity of base frequencies across taxa of genus Phyllostachys using ITS analysis

\begin{tabular}{|c|c|c|c|c|c|c|c|c|c|}
\hline Taxa & & A & $x^{2}$ & $\mathrm{C}$ & $x^{2}$ & G & $x^{2}$ & $\mathrm{~T}$ & $x^{2}$ \\
\hline \multirow{2}{*}{1} & Obs. & 164 & \multirow{2}{*}{0.017} & 218 & \multirow{2}{*}{0.875} & 183 & \multirow{2}{*}{0.022} & 156 & \multirow{2}{*}{0.566} \\
\hline & Exp. & 165.68 & & 204.62 & & 185.02 & & 165.68 & \\
\hline \multirow[b]{2}{*}{2} & Obs. & 145 & \multirow{2}{*}{0.171} & 182 & \multirow{2}{*}{0.060} & 171 & \multirow[b]{2}{*}{0.071} & 155 & \multirow{2}{*}{0.163} \\
\hline & Exp. & 150.06 & & 185.32 & & 167.57 & & 150.06 & \\
\hline \multirow{2}{*}{3} & Obs. & 143 & \multirow{2}{*}{0.354} & 193 & \multirow{2}{*}{0.296} & 185 & \multirow{2}{*}{1.759} & 133 & \multirow{2}{*}{1.989} \\
\hline & Exp. & 150.29 & & 185.6 & & 167.82 & & 150.29 & \\
\hline \multirow{2}{*}{4} & Obs. & 165 & \multirow{2}{*}{1.302} & 169 & \multirow{2}{*}{1.635} & 150 & \multirow{2}{*}{2.050} & 173 & \multirow{2}{*}{3.212} \\
\hline & Exp. & 150.98 & & 186.46 & & 168.59 & & 150.98 & \\
\hline
\end{tabular}

The taxon codes are the same as Table 1. 
Table 7. Maximum Likelihood fits of 24 different nucleotide substitution models

\begin{tabular}{lccccccc}
\hline Model & Parameters & BIC & AICc & $\ln L$ & $(+I)$ & $(+G)$ & $R$ \\
\hline K2+I & 7 & 5266.1 & 5225.7 & -2605.8 & 0.13 & $\mathrm{n} / \mathrm{a}$ & 0.93 \\
T92+I & 8 & 5267.9 & 5221.7 & -2602.8 & 0.12 & $\mathrm{n} / \mathrm{a}$ & 0.93 \\
K2 & 6 & 5268.1 & 5233.4 & -2610.7 & $\mathrm{n} / \mathrm{a}$ & $\mathrm{n} / \mathrm{a}$ & 0.85 \\
K2+G & 7 & 5268.7 & 5228.3 & -2607.1 & $\mathrm{n} / \mathrm{a}$ & 4.41 & 0.89 \\
T92 & 7 & 5269.4 & 5228.9 & -2607.4 & $\mathrm{n} / \mathrm{a}$ & $\mathrm{n} / \mathrm{a}$ & 0.86 \\
T92+G & 8 & 5270.3 & 5224.1 & -2604.0 & $\mathrm{n} / \mathrm{a}$ & 4.49 & 0.89 \\
K2+G+I & 8 & 5272.3 & 5226.1 & -2605.0 & 0.01 & 1.51 & 0.96 \\
T92+G+I & 9 & 5274.0 & 5222.1 & -2601.9 & 0.00 & 1.48 & 0.96 \\
JC+I & 6 & 5277.9 & 5243.2 & -2615.6 & 0.12 & $\mathrm{n} / \mathrm{a}$ & 0.50 \\
JC & 5 & 5278.4 & 5249.6 & -2619.7 & $\mathrm{n} / \mathrm{a}$ & $\mathrm{n} / \mathrm{a}$ & 0.50 \\
HKY+I & 10 & 5278.7 & 5220.9 & -2600.4 & 0.12 & $\mathrm{n} / \mathrm{a}$ & 0.93 \\
JC+G & 6 & 5279.7 & 5245.1 & -2616.5 & $\mathrm{n} / \mathrm{a}$ & 4.39 & 0.50 \\
HKY & 9 & 5280.6 & 5228.6 & -2605.3 & $\mathrm{n} / \mathrm{a}$ & $\mathrm{n} / \mathrm{a}$ & 0.86 \\
HKY+G & 10 & 5281.3 & 5223.5 & -2601.7 & $\mathrm{n} / \mathrm{a}$ & 4.42 & 0.89 \\
JC+G+I & 7 & 5284.1 & 5243.7 & -2614.8 & 0.00 & 1.43 & 0.50 \\
HKY+G+I & 11 & 5284.7 & 5221.2 & -2599.6 & 0.00 & 1.44 & 0.96 \\
TN93+I & 11 & 5285.9 & 5222.4 & -2600.1 & 0.12 & $\mathrm{n} / \mathrm{a}$ & 0.93 \\
TN93 & 10 & 5287.5 & 5229.7 & -2604.8 & $\mathrm{n} / \mathrm{a}$ & $\mathrm{n} / \mathrm{a}$ & 0.86 \\
TN93+G & 11 & 5288.2 & 5224.7 & -2601.3 & $\mathrm{n} / \mathrm{a}$ & 4.37 & 0.90 \\
TN93+G+I & 12 & 5291.9 & 5222.6 & -2599.2 & 0.01 & 1.46 & 0.97 \\
GTR+I & 14 & 5306.3 & 5225.5 & -2598.6 & 0.12 & $\mathrm{n} / \mathrm{a}$ & 0.93 \\
GTR & 13 & 5307.7 & 5232.6 & -2603.3 & $\mathrm{n} / \mathrm{a}$ & $\mathrm{n} / \mathrm{a}$ & 0.86 \\
GTR+G & 14 & 5308.5 & 5227.6 & -2599.7 & $\mathrm{n} / \mathrm{a}$ & 4.48 & 0.89 \\
GTR+G+I & 15 & 5313.5 & 5226.9 & -2598.3 & 0.11 & 11.59 & 0.94 \\
\hline TNF &
\end{tabular}

Models with the lowest BIC scores (Bayesian Information Criterion) are considered to describe the substitution pattern the best. For each model, AICc value (Akaike Information Criterion, corrected), Maximum Likelihood value ( $\ln L$ ), and the number of parameters (including branch lengths) are also presented. Non-uniformity of evolutionary rates among sites may be modeled by using a discrete Gamma distribution $(+G)$ with 5 rate categories and by assuming that a certain fraction of sites are evolutionarily invariable $(+I$ ). Whenever applicable, estimates of gamma shape parameter and/or the estimated fraction of invariant sites are shown. Assumed or estimated values of transition/transversion bias $(R)$ are shown for each model, as well. GTR: General Time Reversible; HKY: Hasegawa-Kishino-Yano; TN93: Tamura-Nei; T92: Tamura 3-parameter; K2: Kimura 2-parameter; JC: Jukes-Cantor.

였다(Table 7). 베이시안 정보 기준은 키무라 척도 5266.1에서 일반 시간 가역 5313.5 로 나타났으며 알카이케 정보 기준도 5225.7에서 5245.1로 유사하였다. 염기치환의 전이/전형의 비 는 0.50 에서 0.96 으로 모델 간 큰 차이를 나타내었다.

타지마(Tajima)의 중립성 검증에서 자리 수는 4 였으며 분리 되는 자리 수는 430 이었으며 이들의 비는 0.715 였고, 다양도는 0.440 으로 높았다(Table 8). 중립설의 검증 결과는 0.5 보다 큰 값을 나타내므로 유전적 변이를 증가시키는 힘이 자연도태 즉, 삽입과 결실에 의한 결실돌연변이설보다는 도태에 의한

Table 8. Results from Tajima's neutrality test for ITS sequences of genus Phyllostachys

\begin{tabular}{cccccc}
\hline $\mathrm{M}$ & $\mathrm{S}$ & $\mathrm{ps}$ & $\theta$ & $\pi$ & $\mathrm{D}$ \\
\hline 4 & 430 & 0.715 & 0.390 & 0.440 & 1.349 \\
\hline
\end{tabular}

$\mathrm{M}=$ number of sites, $\mathrm{S}=$ Number of segregating sites, $\mathrm{ps}=\mathrm{S} / \mathrm{M}$, $\theta=\mathrm{ps} / \mathrm{a} 1$, and $\pi=$ nucleotide diversity. $\mathrm{D}$ is the Tajima test statistic.
중립가설로 설명된다 $(\mathrm{D}=1.349)$.

$\mathrm{MP}$ tree에서 오죽과 분죽이 같은 clade를 이루었으며 이들 은 맹종죽과 sister관계이다(Fig. 1). 왕대가 이들보다 먼저 분 지한 것으로 볼 수 있다. ML tree 역시 오죽과 분죽이 같은 clade를 이루었으나 맹종죽이 아닌 왕대와 sister그룹을 형성 하였다(Fig. 2). NL tree는 역시 오죽과 분죽이 같은 clade를 이루었다(Fig. 3). NL tree는 오죽과 분죽이 맹종죽이 아닌 왕 대와 sister그룹을 형성하여 MP tree보다 ML tree에 더 유사한 양상을 나타내었다. 이 세 tree의 일치하는 것으로 오죽과 분죽 이 더 유연관계가 근연함을 나타내었다. 결론적으로 맹종죽이 나 왕대에서 오죽과 분죽이 분지되어 노온 것으로 판단된다. 맹종죽과 왕대 중에서는 어느 것이 더 조상형에 근연한지는 계통도에 따라 다르므로 본 결과만으로는 판단할 수 없었다.

\section{고 찰}

한국 내 분포하는 왕대속 식물은 연구자들 간 일치된 검색분 


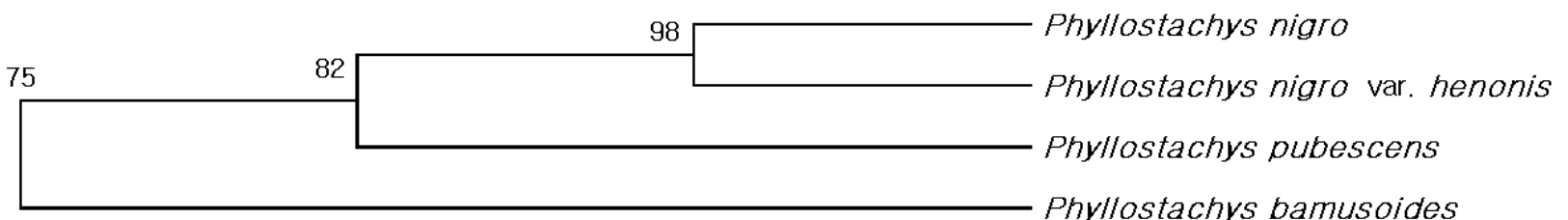

Fig. 1. The maximum parsimonious tree for genus Phyllostachys based on ITS analysis using PAUP 4b10, exhaustive search, unweighted parsimony analysis, gaps=fifth state) from the 751 aligned positions of the initial matrix. The values of bootstrap were shown in side of vertical lines.

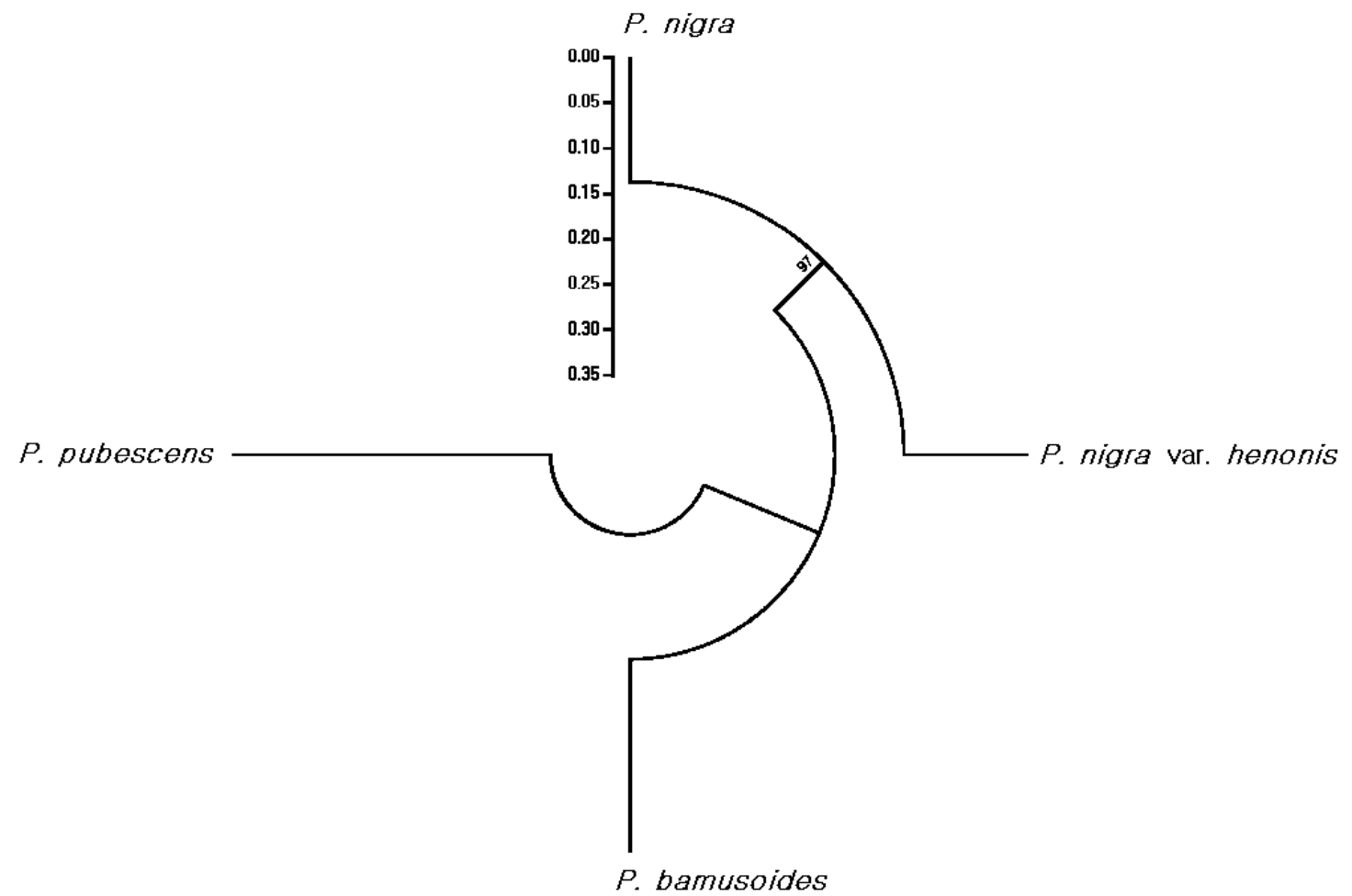

Fig. 2. The maximum likelihood tree for genus Phyllostachys based on ITS analysis using MEGA5. The value of bootstrap was shown in side of lines.

류표가 작성되어 있지 않아 분류하기 어려운 측면이 있다. 즉, 연구자에 의해 종의 동정부터 문제시 되어 도감마다 같은 종이 라도 학명이 달라 누구의 견해를 취해야 할 지 문제시된다[9,10]. 최근 Lee [9]의 개정된 도감에 의해 많이 정리되었다. 그는 왕대 속(genus Phyllostachys), 해장죽속(Genus Arundinaria), 조릿대 속(Genus Sasa)으로 구분하였다. Lee [9]의 도감에서 조릿대속 이 지리적 집단 간 차이를 인정함으로써 지나치게 종을 세분 한 면이 없지 않지만 여기서는 논외이다. 오죽과 분죽은 외부 형태가 닮았으나 오죽은 줄기와 가지가 검은 점이 분죽과 차 이가 있다. 따라서 이 두 분류군은 근연하다는 점에서 본 연구 결과와 일치한다(Figs. 1 3). 다만 오죽(Phyllostachys nigra)을 정명으로 하고, 분죽(Phyllostachys nigra var. henonis)을 변종으
로 취급하는 데는 문제가 있을 수 있다. 첫째, 분죽은 성숙되어 도 줄기와 가지, 잎 등 어느 부위에도 검은색을 가진 형질이 나타나지 않는데 흑색을 의미하는 'nigrá가 종소명으로 들어 가 있다. 오죽은 생육 첫해에는 녹색이 나타내지만 2년이 경과 하면 검은색으로 변하므로 흑색을 의미하는 'nigrá가 종소명 으로 들어가 있는 것이 인정된다. 둘째, 분포지역 관점에서 오죽은 오죽헌을 비롯한 일부 제한된 지역에서 관상용으로 재배된다. 반면에 분죽은 오죽에 비해 넓은 분포지역을 가지 고 있다. 이런 경향은 원산지인 중국에서도 오죽의 분포지 보 다는 분죽의 분포지가 훨씬 광범위하다. 물론 오죽에서 분화 하여 널리 확산되었다고 추론할 수 있지만 그 반대로 분죽의 일부 분포지에서 어떤 원인(예를 들면 색소를 발현하는 유전 


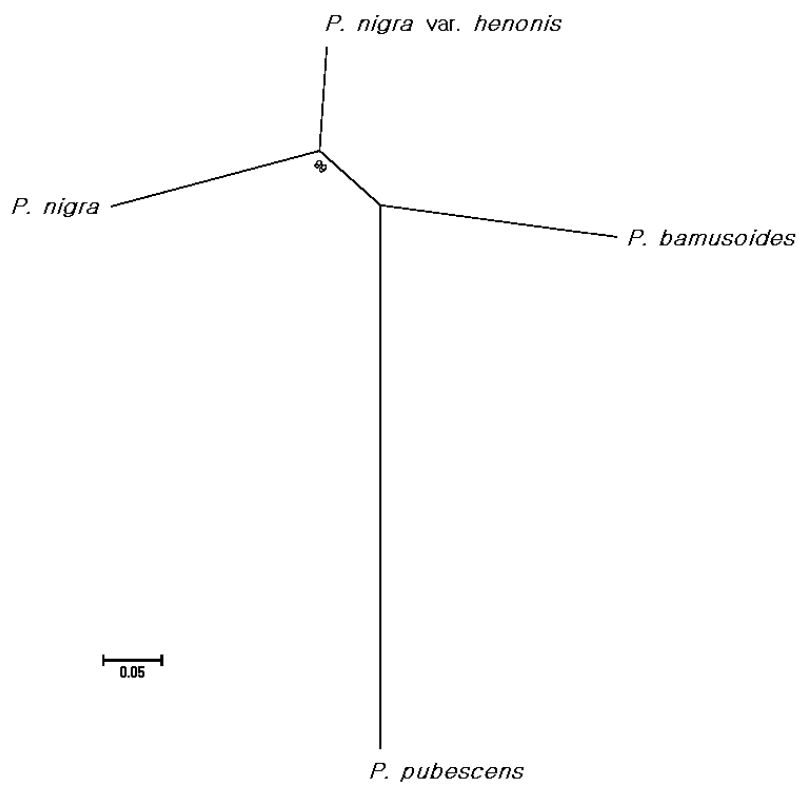

Fig. 3. The neighbor-joining tree for genus Phyllostachys based on ITS analysis using MEGA5. The value of bootstrap was shown in side of line.

자에 돌연변이가 발생)으로 검은색 오죽이 분화되어 그 색의 특이성으로 여러 사람들이 선호하여 우리나라로 도입되었을 가능성이 높다. 셋째, 두 번째와 관련이 있는 것으로 대나무에 흑색이라는 특이성으로 우리나라로 도입되었음에도 불구하 고 분죽이 더 많이 분포하고 있다는 것은 오죽을 도입할 당시 이미 분죽이 분포되어 있었을 것이다. 따라서 분죽에서 오죽 이 분화되었다면 변종을 오죽으로 취급해야 보다 정확한 계통 분류를 반영한 것으로 볼 수 있다.

한편 앞서 inter-simple sequence repeats (ISSR) 마커에 의 한 연구[6]와 random amplified polymorphic DNA (RAPD) 마커에 의한 연구[7]를 본 연구인 핵 내 리보솜 서열(ITS) 연구 결과와 비교하였다. ISSR 마커에 의한 결과와 본 연구의 계통 도는 거의 유사하였다. 그러나 RAPD 마커에 의한 연구에서는 오죽이 분죽보다는 맹종죽과 더 근연한 것으로 나타났다. 이 결과는 형태학적 관점에서 오죽이 분죽이 수고, 색소 등이 맹 종죽보다 더 유사하므로 부합하지 않는다. 한편 RAPD 마커에 의한 다양도(genetic diversity=0.044), ISSR 마커에 의한 다양 도(0.098), ITS의 결과에서 얻은 다양도(0.440)가 더 높았는데 이는 exon 보다는 intron 부위에서 서열 간 변이가 많고 보다 긴 서열을 분석하여 다양도가 높게 나타난 것으로 판단된다.

대나무는 근대 산업 사회로 접어든 이래 플라스틱이나 철제 재료의 대체로 인해 사양 산업으로 간주되어왔다. 그러나 전 라남도 담양군 등에서는 대나무 연구소와 죽녹원 등 연구와 관광 사업으로 크게 발전되고 있고 특히 값싼 동남아 대나무 죽제품보다는 죽순을 이용한 먹거리 생산이 크게 신장되고 있으며 친환경적 소재로 죽제품이 다시 각광을 받고 있다. 특
히 우리나라가 아열대 기후로 접어들면 대나무 생육이 크게 증대되어 강변 산책로, 가로수 등 우리 주변의 사계절 녹지와 산소배출에 크게 기여할 것이다. 이런 관점에서 가장 기본적 인 종 분류에 ITS에 의한 결과가 형태학적 분류와 매우 일치하 는 것과 다양성 측정에 매우 정보적으로 본 연구결과에서 입 증되었다.

\section{References}

1. Backmann, K. 2001. Evolving and the genetic analysis of populations: 1950-2000. Taxon 50, 7-45.

2. Baldwin, B. G, M. J. Sanderson, J. M. Porter, M. F. Wojciechowski, C. S. Campbell, and M. J. Donoghue. 1995. The ITS region of nuclear ribosomal DNA: a valuable source of evidence on angiosperm phylogeny. Ann. Mo. Bot. Gard 82, 247-277.

3. Bonnard, G., F. Michel, J. H. Well, and A. Steinmetz. 1984. Nucleotide sequence of the $\mathrm{tRNA}^{\mathrm{Leu}}$ gene from Vicia faba chloroplasts: evidence for structural homologies of the tRNA $^{\text {Leu }}$ intron with intron from the autosplicable Tetrahymena ribosomal RNA precursor. Mol. Gen. Genet. 194, 330-336.

4. Cech, T. R. 1988. Conserved sequences and structures of group I introns: building an active site for RNA catalysis - a review. Gene 73, 259-271.

5. Felsenstein, J. 1993. PHYLIP (Phylogeny Inference Package) version 3.5s, Distributed by the author. Department of Genetics, Univ. Washington, Seattle.

6. Kumar, S. and S. R. Gadagkar. 2001. Disparity Index: A simple statistic to measure and test the homogeneity of substitution patterns between molecular sequences. Genetics 158, 1321-1327.

7. Lee, S. J., M. K. Huh, and H. W. Huh. 2007. Genetic diversity and phylogenetic relationship of genus Phyllostachys by ISSR markers. J. Life Sci. 17, 1482-1487.

8. Lee, S. J., M. K. Huh, H. C. Shin, and H. W. Huh. 2010. Genetic diversity and phylogenetic relationship of genus Phyllostachys by RAPD markers. J. Life Sci. 20, 819-824.

9. Lee, T. B. 2003. Coloured Flora of Korea. Hyangmoon-sa, Seoul. Korea.

10. Lee, Y. N. 2007. New Flora of Korea. Kyo-Hak Publishing Co., Seoul. Korea.

11. Michel, F. and B. Dujon. 1983. Conservation of RNA secondary structures in two intron families including mitochondrial-, chloroplast- and nuclear-encoded members. EMBO J. 2, 33-38.

12. Nei, M. 1973. Analysis of gene diversity in subdivided populations. Proc. Natl. Acad Sci. USA. 70I, 3321-3323.

13. Nei, M. and S. Kumar. 2000. Molecular Evolution and Phylogenetics. Oxford University Press, NY.

14. Saitou, N. and M. Nei. 1987. The neighbor-joining method: A new method for reconstructing phylogenetic trees. $\mathrm{Mol}$. Biol. Evol. 4, 406-425.

15. Swofford, D. L. 2003. PAUP*. Phylogenetic Analysis Using 
Parsimony ("and other methods). Version 4. Sunderland, Sinauer Associates, Inc. MA.

16. Tajima, F. 1989. Statistical methods to test for nucleotide mutation hypothesis by DNA polymorphism. Genetics 123, 585-595.

17. Tamura, K., D. Peterson, N. Peterson, G. Stecher, M. Nei, and S. Kumar. 2011. MEGA5: Molecular evolutionary genetics analysis using maximum likelihood, evolutionary dis- tance, and maximum parsimony methods. Mol. Biol. Evol. (In Press).

18. White, T. J., T. Bruns, S. Lee, and J. Taylor. 1999. Amplification and direct sequencing of fungal ribosomal genes for phylogenetics, pp. 315-322, In Innis M. A., D. H. Gelfand, J. J. Sninsky, and T. J. White (eds.), PCR Protocols: $A$ Guide to Methods and Applications, New York Academic press.

\section{초록 : ITS 서열에 의한 한국 왕대속 식물종의 계통분류학적 연구}

이송진 ${ }^{1} \cdot$ 허만규 $^{2} *$ 허홍욱 $\cdot$ 이병룡 ${ }^{3}$

( ${ }^{1}$ 부산대학교 생물교육과, ${ }^{2}$ 동의대학교 분자생물학과, ${ }^{3}$ 서원대학교 과학교육과)

왕대속은 벼과 또는 화본과에 속하는 다년생 목본성 초본이며 아시아의 인도와 중국에 많은 종이 주로 분포한 다. 식물에서 속간 속내 계통관계 추론을 위해 널리 이용되고 있는 ITS 부위가 있다. 이 속에 속하는 우리나라 자생 식물 왕대 속내 네 식물종 간 계통 관계를 평가하기 위해 핵 게놈의 ITS 부위로 평가하였다. DNA 서열 배당은 많은 갭(gaps)을 가지고 있었다. 이 속 내 서열 변이는 일부 삽입과 결실이 발견되었고 속내 종간 변이는 자연도태에 의한 것으로 밝혀졌다. 이 속의 오죽과 분죽은 세 계통도( $\mathrm{MP}, \mathrm{ML}$, and $\mathrm{NJ})$ 에서 모두 같은 분지군을 형성하여 가장 근연관계에 있었다. 기존의 형태학적 특성과 단순 반복 서열(ISSR)의 결과와 유사한 계통 관계를 나타내어 왕대속에서 ITS의 서열이 이들 분류군에 매우 유익한 정보를 제공하고 있음을 시사하였다. 